\title{
Axillary Dissection in the Case of Positive Sentinel Lymph Nodes: Results of the Innsbruck Consensus Conference
}

\author{
Axilladissektion bei positivem Sentinel-Lymphknoten: \\ Ergebnisse Innsbrucker Konsensuskonferenz
}

Authors

Affiliations

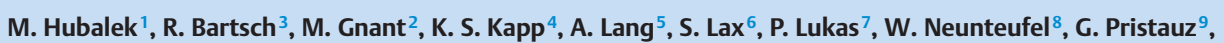
R. Reitsamer ${ }^{10}$, P. Sandbichler ${ }^{11}$, P. Schrenk ${ }^{12}$, C. Singer ${ }^{14}$, K. Tamussino ${ }^{9}$, J. Tschmelitsch ${ }^{13}$, A. G. Zeimet ${ }^{1}$, C. Marth

The affiliations are listed at the end of the article

\section{Key words}

- sentinel lymph node

- axillary dissection

- ACOSOG-Z0011

- breast cancer

Schlüsselwörter

- Sentinel-Lymphknoten

- Axilladissektion

- ACOSOG-Z0011

- Brustkrebs received 21.12.2011

accepted 29.2.2012

Bibliography

DOI http://dx.doi.org/

10.1055/s-0031-1298441

Geburtsh Frauenheilk 2012; 72:

293-298 @ Georg Thieme

Verlag KG Stuttgart · New York

ISSN 0016-5751

Correspondence

Dr. Michael Hubalek, MD

Medizinische Universität

Innsbruck, Brustgesundheits-

zentrum Tirol, Universitäts-

Frauenklinik Innsbruck

Anichstraße 35

6020 Innsbruck

Österreich

michael.hubalek@i-med.ac.at

\section{Abstract}

$\nabla$

The prognosis of breast cancer is most heavily influenced by the status of the axillary nodes. Until a few years ago, this knowledge was gained through radical axillary lymph node clearance. In the meantime, sentinel lymph node clearance has become an established part of the surgical treatment of breast cancer. With the development of this procedure, the morbidity caused by axillary dissection has been reduced significantly. Although comprehensive prospective, randomised data regarding the safe use of the sentinel concept are only now available, the focus currently, however, is on the question of whether in the case of positive sentinel lymph nodes, an axillary dissection can be done away with altogether without having any negative impact on the risk of loco-regional recurrence or on progression-free survival and overall survival. The results of the American ACOSOG-Z001 study have changed the fundamental perspective of this. In this study on the advantages of axillary dissection following the confirmation of tumour tissue in the sentinel lymph nodes, there were no statistically significant advantages from axillary dissection for women with a favourable overall risk profile who had received radiotherapy and systemic therapy. If this concept takes hold, the surgical treatment of node-positive breast cancer, at least in the axilla, would be reduced to a minimum, and the focus of treatment would in future lie more on the systemic treatment of this condition. As part of an interdisciplinary consensus meeting, a standardised approach for Austria with regard to this question was decided upon.

\section{Zusammenfassung \\ $\nabla$}

Die Prognose des Mammakarzinoms wird durch den axillären Lymphknotenstatus am stärksten beeinflusst. Dieses Wissen wurde noch bis vor wenigen Jahren durch die radikale axilläre Lymphonodektomie erlangt. Inzwischen ist die Sentinel-Lymphonodektomie etablierter Bestandteil in der operativen Behandlung des Mammakarzinoms geworden. Durch die Entwicklung dieses Verfahrens konnte die Morbidität, die durch eine axilläre Dissektion verursacht wird, wesentlich reduziert werden. Wenngleich erst jetzt umfassende prospektiv randomisierte Daten zur sicheren Anwendung des Sentinel-Konzepts vorliegen, geht es aktuell jedoch bereits um die Frage, ob bei positivem Sentinel-Lymphknoten auf eine Axilladissektion (AD) gänzlich verzichtet werden kann, ohne das Risiko für ein lokoregionäres Rezidiv oder das progressionsfreie Überleben und Gesamtüberleben negativ zu beeinflussen. Die Ergebnisse der amerikanischen ACOSOG-Z0011Studie haben die grundlegende Betrachtungsweise verändert. In dieser Studie zum Vorteil der Axilladissektion nach Tumornachweis im Sentinel-Lymphknoten ergaben sich für die Patientinnen mit günstigem Gesamtrisikoprofil und applizierter Strahlentherapie und systemischer Therapie keine statistisch signifikanten Vorteile durch die Axilladissektion. Setzt sich dieses Konzept durch, wäre die operative Versorgung des nodalpositiven Mammakarzinoms zumindest in der Axilla auf ein Minimum reduziert und der Fokus der Behandlung läge zukünftig mehr in der systemischen Behandlung dieser Erkrankung. Im Rahmen eines interdisziplinären KonsensusMeetings wurde eine einheitliche Vorgehensweise für Österreich diese Fragestellung betreffend beschlossen. 


\section{Introduction}

$\nabla$

Surgical treatment for breast cancer has evolved from the routine radical mastectomy towards much less mutilating procedures; the establishment of the breast-conserving treatment concept in particular represents a major step forward. Although the procedure has changed markedly with regard to the primary tumour over the last few decades, axillary dissection was until recently the standard therapy both for node-positive and node-negative patients with breast cancer. Thanks to the clinical establishment and validation of the concept of the sentinel lymph nodes in the surgical treatment of breast cancer, axillary dissection is no longer needed in patients with negative sentinel lymph nodes [1]. The morbidity associated with the axillary dissection has also been markedly reduced. Axillary lymph node clearance remains the standard procedure, however, for women who have metastatic sentinel lymph nodes. A recent study result [2] now postulates that it may be possible to spare some women from this common, guideline-confirming practice altogether.

The Halsted theory, which assumes a local spread of the disease, has recently been called into question in quite an impressive manner by the groundbreaking work of the NSABP. In the B-04 study of the National Surgical Adjuvant Breast and Bowel Project (NSABP) [3], women with breast cancer were randomised into 5 treatment groups. Patients with palpable lymph nodes were given a radical Halsted mastectomy or a simple mastectomy followed by regional radiotherapy. Patients without clinically pathological or palpable lymph nodes were randomised into 3 different study arms: radical Halsted mastectomy (with axillary dissection), total mastectomy with regional radiotherapy, or mastectomy without further local treatment followed by axillary dissection in the case of axillary lymph node recurrence. In the group who had radical (Halsted) surgery, occult axillary lymph node metastasisation was found in $40 \%$ of cases. Despite an axillary recurrence rate of $19 \%$ in the group who received a simple mastectomy, survival after 25 years was identical in all three treatment arms.

Many other investigations which showed that the radical removal or treatment of axillary lymph nodes offered no advantage in terms of survival helped to develop and clinically validate the concept of sentinel lymph nodes. This technique has now replaced axillary lymph node clearance according to level I and II for the staging of axillary lymph nodes in the treatment of early breast cancer. The recently-published study by Veronesi et al. [4] demonstrated that in 516 women after a 10-year follow-up, both the local recurrence rate and the DFS between the negative SLN biopsy alone or in combination with axillary dissection were the same. The difficulty of "proving" any actual lack of difference lies in the extreme rareness of axillary recurrence.

Retrospective studies reveal that axillary dissection does not need to be carried out for positive SLN under certain conditions. However, in view of the retrospective nature of these analyses, these data are only of limited use for practice since they cannot in principle define any clinical standard. As an overview, these results show an altogether low local axillary recurrence rate in patients with positive SLN who did not have axillary dissection. The risk of local recurrence in these reports was lower the older the patient, the smaller the primary tumour, the more differentiated the tumour and the smaller the metastasis in the sentinel lymph node, assuming breast-conserving treatment however. In the retrospective work by Bilimoria et al. [5], which included over 400000 patients from the SEER database, no axillary dissection was carried out in $21 \%$ of patients for various reasons despite positive SLN. Patients with axillary dissection had neither a survival advantage nor a lower local recurrence rate than patients in whom no axillary dissection was performed. This result relates both to micrometastases and macrometastases in the SLN. The Dutch MIRROR study [6], however, clearly showed the prognostically unfavourable value of disseminated tumour cells or micrometastases in SLN, particularly in patients who had not received any corresponding adjuvant systemic therapy. Axillary dissection, however, yielded no improvement in survival for these patients.

In a further study by Yi et al. [7], 27000 patients with node-positive breast cancers from the SEER database were analysed retrospectively. In their paper, the authors report that patients with SLN and subsequent AD had a poorer disease-specific survival than patients who only received an SLN biopsy. One possible explanation speculated for this surprising result is that women who had had both procedures were already suffering a more advanced form of the disease. This assumption was supported by the fact that the tumours in the group with $\mathrm{AD}$ were more frequently larger and hormone receptor-negative. In contrast to this, among patients with micrometastases $(0.2-2 \mathrm{~mm})$, there was no difference in terms of disease-specific survival between the two groups (SLN alone vs. SLN followed by AD). The authors deduced from these results that the advantages of avoiding axillary dissection need to be weighed against the risks of occult axillary lymph node metastasis.

With regard to micrometastases in the SLN however, the data are now very clear: the meta-analysis by the Early Breast Cancer Trialists' Collaborative Group of a total of 78 randomised studies (42 000 patients) from the "pre-SLN" era assumes that differences in the local control of $10-20 \%$ after 5 years' follow-up are manifested in a statistically significant difference ( $5 \%$ absolute risk reduction) in survival after 15 years [8]. In order to achieve this difference in the local recurrence rate by doing away with axillary dissection, the further nodal involvement in the case of micrometastasis in the SLN must exceed the 30\% mark, which does not fit with the current data.

Based on current medical knowledge, it can be assumed that patients with micrometastases in the SLN gain little or no benefit apart from the prognostic information - from axillary dissection. These indirect and retrospective results, however, cannot ultimately suffice for changing a clinical standard, although this ultimately occurred very early in the case of the implementation of the SLN without adequate clinical studies.

The American ACOSOG study group has recently published the Z0011 study, which investigated the value of axillary lymph node dissection (ALND) for sentinel-positive breast cancers [2]. The inclusion criteria were: Tumour size less than $5 \mathrm{~cm}$, max. 2 positive SLN (micro- or macrometastasis in the HE stain); exclusion criteria included patient breast irradiation, intentional axillary irradiation, SN metastases confirmed only immuno-histochemically, LN capsule breakthrough in the SLN and patients who had had a mastectomy. 856 patients were included in the "intention to treat analysis". In 106 cases (27.4\%) with positive SN, further positive lymph nodes were demonstrated in the ALND. After a median follow-up time of 6.3 years, the ALND had no influence on the disease-free survival, overall survival or loco-regional recurrence rate.

It is as yet unclear to what extent these results were influenced by adjuvant radiotherapy. In the Z0011 study, almost all patients were given radiotherapy as planned to the breast that had been 
operated on following breast-conserving surgery. Since no quality assurance of the radiotherapy was carried out, it is unclear whether and to what extent axillary lymph node stations were included in the irradiation. Debate therefore continues regarding whether the low rate of axillary recurrences is due to unplanned irradiation of the axilla or not. One weakness of this prospective study is that the study was closed after 891 patients, before the planned number of 1900 patients was reached, due to slow recruitment. Moreover, the relatively large number of participating centres were each only able to recruit a small number of patients. Also of note is the fact that over $30 \%$ of the patients included in the study only had micrometastases in the sentinel lymph nodes, which means that a selection of patients with a low biological risk cannot be excluded.

The conclusion of the authors of the study was that, in the case of positive sentinel lymph nodes, routinely conducted axillary lymph node dissection in patients with clinically negative axillae is not always justified. This conclusion created quite a stir both nationally and internationally and ultimately also led to some uncertainty with regard to the treatment of patients with breast cancer.

\section{Question}

\section{$\nabla$}

It was therefore a major challenge for the Austrian Society of Gynaecology and Obstetrics as well as for the Working Group for Gynaecological Oncology to define a standard at least at the national level that would give surgeons greater confidence regarding treatment. For this reason, a Consensus Conference was organised with international delegates.

\section{Methods}

\section{$\nabla$}

The Austrian Society of Gynaecology and Obstetrics (ÖGGG) and the Working Group for Gynaecological Oncology (AGO) invited renowned specialists in the field of the diagnosis and treatment of breast cancer to take part in this Consensus Conference. The 15 members of the panel were (in alphabetical order): Bartsch Rupert (Medical Oncology), Gnant Michael (Surgery), Hubalek Michael (Gynaecology), Kapp Karin (Radio-Oncology), Lang Alois (Medical Oncology), Lax Sigurd (Pathology), Marth Christian (Gynaecology), Lukas Peter (Radio-Oncology), Neunteufel Walter (Gynaecology), Reitsamer Roland (Gynaecology), Sandbichler Peter (Surgery), Schrenk Peter (Surgery), Tamussino Karl (Gynaecology), Tschmelitsch Jörg (Surgery), Zeimet Alain (Gynaecology). Consequently, the interdisciplinary panel was made up of $33 \%$ gynaecologists, $27 \%$ surgeons, $15 \%$ medical oncologists, $15 \%$ radio-oncologists and $10 \%$ pathologists. None of the panellists declared any conflict of interest in relation to the vote.

The audience ( 123 people) at the conference was made up of $25 \%$ surgeons, $57 \%$ gynaecologists, 5\% medical oncologists, $5 \%$ pathologists and 8\% radio-oncologists. Questions were drawn up in advance that were to form the basis of the conference.

The conference itself was in two parts: the first part presented the retrospective and prospective data, with two study investigators from the ACOSOG Z0011 study being invited along for this (Elizabeth A. Mittendorf, M.D., Assistant Professor, Department of Surgical Oncology, Division of Surgery, The University of Texas MD Anderson Cancer Center, Houston, Texas; Eric A. Strom, M.D., F.A.C.R., Professor, Department of Radiation Oncology, Division of Radiation Oncology, The University of Texas MD Anderson Cancer Center, Houston, TX). The panel and the audience then had the opportunity to discuss the results further on the basis of the questions asked. The questions were voted on separately via a voting system by the panel and the audience, and the results also announced to each group separately.

\section{Results ( 0 Table 1) \\ $\nabla$}

Question 1: Are the results of the ACOSOG Z0011 study sufficient to change our clinical practices?

The discussion of the Consensus Conference was commenced following presentation of the studies and the retrospective literature, centred around the principle question of whether the results of a single study could be sufficient to change clinical practices. Ultimately, the debate produced a resonant vote for the fact that in exceptional cases even a single study - provided it was planned and executed well - can be sufficient to change routine measures. This is particularly true for epistemological threshold territories, provided the studies display an excellent standard of quality. However, a few limitations were pointed out for the ACOSOG Z0011 study with regard to this latter point. Ultimately, it was not surprising that the panel was split evenly, with $38 \%$ of the panel voting "yes" and 38\% voting "maybe", with $25 \%$ voting "no". The audience, however, returned a clear majority for "maybe", which can be equated to a limited use of the results.

\section{Question 2: Is axillary dissection necessary}

if isolated tumour cells have been immunohistochemically confirmed in the SLN?

This question was only discussed briefly in light of the current guidelines and the recent data. Sole confirmation of isolated tumour cells has already been classified so far as node negative and $i+$. It was therefore not surprising that the overwhelming majority of the panel and of the audience (94 and 93\% respectively) voted no.

\section{Question 3: Should the immuno-histochemical confirmation of tumour cells in the sentinel node continue to be carried out?}

Since the sole immuno-histochemical confirmation of tumour cells has no major importance in relation to clinical decisionmaking, the debate was characterised more by method-related and diagnostic aspects. The pathologists in particular expressed the opinion that immuno-histochemistry can continue to be helpful for the correct diagnosis of micrometastases and small macrometastases in the sentinel lymph node. In the case of lobular carcinomas in particular, the detection of metastases or the determination of the exact size of the metastasis can be difficult, and the use of cytokeratin immuno-histochemistry can be crucial [9]. With regard to the decision regarding whether axillary lymph node dissection should be carried out or not, the result of a immuno-histochemical confirmation of tumour cells is irrelevant. This opinion is reflected in the outcome of the vote.

Question 4: Is axillary dissection necessary where there are micrometastases in the sentinel lymph nodes?

So far in Austria, axillary dissection has been indicated as a routine procedure if such findings are present. In light of the retrospective data available, the recommendations of the St. Gallen Consensus Meeting in 2011 and ultimately the ACOSOG Z0011 
study, the majority of speakers in the debate expressed the opinion that the benefits of axillary dissection are highly questionable. In particular, it is not anticipated that any major change will occur in adjuvant therapy since the likelihood of relevant metastases, even macrometastases, in further non-sentinel lymph nodes is very low. It must be pointed out, however, that an arbitrary margin of $2 \mathrm{~mm}$ is naturally not rooted in true biological principles, and therefore other prognostic factors, such as highly malignant phenotypes, must also be taken into account. Ultimately, the panellists and the audience voted in unison at $80 \%$ against further axillary dissection for micrometastases in the sentinel lymph nodes.

Question 5: Is axillary dissection necessary where there are macrometastases in the sentinel lymph nodes?

During the debate, considerable criticism was levied at the ACOSOG Z0011 study, which prevents the direct implementation of the results for everyday clinical practice. The importance of clear restrictions was particularly pointed out, and a general dispensation with axillary dissection was considered unfeasible. For this reason, the result of $80 \%$ yes votes on the panel and $82 \%$ yes votes in the audience was not surprising. In light of these results, however, the question was further discussed as to whether the findings should only be applied to a subgroup of patients.

Question 6: Should patients who have good prognostic factors (post-menopausal, hormone receptor positive, histological grading I + II, low Ki67) continue to have axillary dissection for macrometastases in a sentinel lymph node?

It was particularly pointed out that the biological properties of the tumour may be more important than the size of the metastasis and that the patient group described in the question could dispense with axillary dissection in view of the low likelihood of recurrence, in particular the low likelihood of finding further positive lymph nodes. $79 \%$ of the panel and $71 \%$ of the audience were of the opinion that axillary dissection was probably not absolutely necessary in this low-risk group. This subgroup essentially also corresponds to the population that was ultimately recruited with priority (and probably selectively) into the ACOSOG Z0011 study. Although the inclusion criteria were officially broader, the patient group included in the study was markedly restricted.

Good prognostic factors were defined as follows: histological grade I and II, moderate to high positive oestrogen and/or progesterone receptor, HER2 negative, Ki67 $<20 \%$, tumour size $<5 \mathrm{~cm}$ (corresponding to pT1 and pT2), and no vascular involvement.

Question 7: Should patients who have poor prognostic factors (pre-menopausal, hormone receptor negative, HER-2 positive, grade III, high Ki67) continue to have axillary dissection for macrometastases in a sentinel lymph node?

This question was implied from the above. In this case, $100 \%$ of the panellists and the audience voted that axillary dissection should always be aimed for.

Poor prognostic factors were defined as follows: histological grade III, weak to negative oestrogen and progesterone receptor, HER2 negative/positive, Ki67 > 20\%, tumour size $>5 \mathrm{~cm}$ (corresponding to pT3 and pT4), and vascular involvement.
Question 8: How should patients with mastectomy be treated? Can the criteria as for breast-conserving surgery also be applied?

The ACOSOG Z0011 study included only patients who had had breast-conserving surgery and therefore also subsequent irradiation. Since no findings can be drawn regarding mastectomy, the debate was relatively unanimous that the results of the study cannot be applied to patients with mastectomy and no radiotherapy. $72 \%$ of the panel and $64 \%$ of the audience continue to believe there is an indication for axillary dissection in the case of positive sentinel lymph nodes in women who have had a mastectomy.

\section{Question 9: Should intra-operative frozen section} analysis of the SLN be carried out in future?

In light of the new findings, the question now arises over whether an intra-operative frozen section analysis of the sentinel lymph node would be helpful. It is however possible, in those patients who do not meet any of the criteria for dispensation with axillary dissection, to make a final decision regarding dissection through frozen section analysis and complete the surgical procedure in a single session. It is probably for this reason that ultimately $73 \%$ of the panellists and $74 \%$ of the audience voted for the routine performance of intra-operative frozen section analysis.

\section{Question 10: How should the axillary lymph nodes} be assessed pre-operatively?

Since the sentinel lymph node biopsy and ultimately also the axillary dissection depend on the pre-operative assessment of lymph nodes, this question was also discussed in detail. For now, it was felt that there was no place for new imaging methods, such as MRI or PET, in everyday clinical practice for imaging of the axilla. The majority of delegates, both at the podium and in the audience, were of the opinion that the lymph nodes should be assessed clinically and with ultrasound. A single clinical palpation was supported by only a minority of delegates.

One of the points of criticism levied at the ACOSOG Z0011 study was the lack of quality assurance of the radiotherapy, which raised questions as regards to whether parts of the axilla had been irradiated too. A lack of difference in the recurrence and overall survival rate was felt by some critics of the study as being a result of this type of radiotherapy. The question therefore arose of whether the axilla be should electively irradiated in future. During the debate, however, the opinion was clearly voiced that under no circumstances should a more conservative operation be replaced by more extensive radiotherapy. The argument that axillary dissection is associated with a higher level of late toxicity than selective irradiation of the axilla is consequently not tenable, since there have been no comparative data so far. For this reason, a change to radiotherapy guidelines was rejected by the radio-oncologists present in the debate.

\section{Summary}

$\nabla$

The Innsbruck Consensus Conference has set forth clear recommendations for the continued practice of axillary dissection (AD) for positive sentinel lymph nodes (SLN) ( Table 2). In the case of isolated tumour cells and micrometastases, axillary dissection can generally be dispensed with in future. AD may continue to be indicated, however, in individual cases where the tumour is of an extremely unfavourable molecular and clinico- 
Table 1 Results of the vote of the panel and audience at the Innsbruck Consensus Conference: The panel and audience voted separately and independently of each other.

\begin{tabular}{|c|c|c|c|}
\hline & & Panel (\%) & Audience (\%) \\
\hline \multirow[t]{3}{*}{ Are the results of the ACOSOG Z011 study sufficient to change our clinical practices? } & Yes & 38 & 16 \\
\hline & No & 25 & 31 \\
\hline & Maybe & 38 & 53 \\
\hline \multirow{2}{*}{$\begin{array}{l}\text { Is axillary dissection necessary following immuno-histochemical confirmation } \\
\text { of isolated tumour cells in the SLN? }\end{array}$} & Yes & 6 & 7 \\
\hline & No & 94 & 93 \\
\hline \multirow{2}{*}{$\begin{array}{l}\text { Should immuno-histochemical confirmation of tumour cells in the SLN } \\
\text { continue to be carried out? }\end{array}$} & Yes & 44 & 78 \\
\hline & No & 56 & 22 \\
\hline \multirow[t]{2}{*}{ Is an axillary dissection necessary for micro-metastases in the SLN? } & Yes & 20 & 20 \\
\hline & No & 80 & 80 \\
\hline \multirow[t]{3}{*}{ How should the axillary lymph nodes be assessed pre-operatively? } & Clinically & 20 & 7 \\
\hline & $\mathrm{CL}+\mathrm{US}$ & 73 & 75 \\
\hline & $\mathrm{CL}+\mathrm{US}+\mathrm{MRI} / \mathrm{PET}$ & 7 & 18 \\
\hline \multirow{2}{*}{ Is an axillary dissection necessary for macro-metastases in the SLN? } & Yes & 80 & 82 \\
\hline & No & 20 & 18 \\
\hline \multirow{2}{*}{$\begin{array}{l}\text { Is ONE prospective study and the available retrospective data sufficient } \\
\text { to change clinical standards? }\end{array}$} & Yes & 38 & 37 \\
\hline & No & 63 & 63 \\
\hline \multirow{2}{*}{$\begin{array}{l}\text { Should the findings be applied to a subgroup of patients? } \\
\text { (postmenopausal status, ER+, grade I + II, low Ki67 [<20\%]) }\end{array}$} & Yes & 79 & 71 \\
\hline & No & 21 & 29 \\
\hline \multirow{2}{*}{$\begin{array}{l}\text { Should patients from a high-risk sub-group be excluded on the basis of the findings? } \\
\text { (premenopausal status, ER-, grade III, high Ki67 [>20\%]) }\end{array}$} & Yes & 100 & 95 \\
\hline & No & 0 & 5 \\
\hline How should patients with a mastectomy be treated? & Yes & 28 & 36 \\
\hline The same procedure as for $\mathrm{BET}$ ? & No & 72 & 64 \\
\hline \multirow[t]{2}{*}{ Should intra-operative frozen sections of the SLN be carried out in future? } & Yes & 73 & 74 \\
\hline & No & 27 & 26 \\
\hline
\end{tabular}

$\mathrm{CL}$ = clinical palpation, $\mathrm{US}=$ ultrasound, $\mathrm{MRI}$ = magnetic resonance imaging, $\mathrm{PET}=$ positron emission tomography

Table 2 Recommendations of the Innsbruck Consensus Conference: The information relates exclusively to patients who have received breast-conserving therapy. Good prognostic factors were defined according to the following criteria: histological grade I and II, moderate to high positive oestrogen and/or progesterone receptor, HER2 negative, Ki67 $<20 \%$, tumour size $<5 \mathrm{~cm}$ (corresponding to pT1 and pT2), and no vascular involvement.

\begin{tabular}{ll} 
Disseminated tumour cells (nano-metastases) & No axillary dissection \\
Micro-metastases $(<2 \mathrm{~mm})$ & No axillary dissection \\
\hline Macro-metastases $(>2 \mathrm{~mm})$ & Axillary dissection is performed except for prognostically favourable tumours
\end{tabular}

pathological nature. With regard to macrometastases, the opinion was that axillary dissection should not generally be dispensed with, but in the case of macrometastases in a sentinel lymph node (see question 6) and the presence of particularly favourable prognostic factors such as positive hormone receptor status, HER-2 negativity, G1 and G2 tumours in post-menopausal women, it can be considered. This corresponds in part to the patients that were included in the ACOSOG Z0011 study. It was suggested during the debate that a register for the prospective collection of axilla data be initiated in Austria. This would also allow a national evaluation of long-term outcomes that may confirm the findings so far, but which may also refute them.

\section{Conflict of Interest}

\section{$\nabla$}

None.

\section{Affiliations}

${ }^{1}$ Department of Women's Health, Clin. Dept. of Gynaecology and Obstetrics, Innsbruck, Austria

2 University Department of Surgery, Breast Health Centre MUW/AKH, Comprehensive Cancer Center Vienna, Medical University of Vienna, Vienna, Austria

${ }^{3}$ University Department of Internal Medicine I, Breast Health Centre MUW/ AKH, Comprehensive Cancer Center Vienna, Medical University of Vienna, Vienna, Austria

${ }^{4}$ University Department of Radiotherapy/Radio-Oncology, Graz, Austria

${ }^{5}$ Feldkirch State Hospital, Dept. of Internal Medicine, Haematology and Medical Oncology, Feldkirch, Austria

${ }^{6}$ Graz West State Hospital, Institute of Pathology, Graz, Austria

7 University Department of Radiotherapy/Radio-Oncology, Innsbruck, Austria

${ }^{8}$ Dornbirn Hospital, Department of Gynaecology and Obstetrics, Dornbirn,

Austria

${ }^{9}$ University Department of Gynaecology and Obstetrics, Clinical Department of Gynaecology, Graz, Austria

${ }^{10}$ St. Johanns-Spital/State Women's Hospital, University Department of Specialist Gynaecology, Salzburg, Austria

11 St.Vinzenz Hospital, Department of Surgery, Zams, Austria

12 Linz City Hospital, Dept. of Surgery II, Breast Competence Centre, Linz, Austria

${ }^{13}$ Hospital of the Merciful Brothers, Surgical Department, St. Veit/Glan, Austria

${ }^{14}$ Clinical Department of General Gynaecology and Gynaecological Oncology, Medical University of Vienna, Vienna, Austria 


\section{References}

1 Mansel RE, Fallowfield L, Kissin $M$ et al. Randomized multicenter trial of sentinel node biopsy versus standard axillary treatment in operable breast cancer: the ALMANAC trial. JNCI 2006; 98: 599-609

2 Giuliano AE, Hunt KK, Ballman KV et al. Axillary dissection vs. no axillary dissection in women with invasive breast cancer and sentinel node metastasis: a randomized clinical trial. JAMA 2011; 305: 569575

3 Fisher B, Jeong JH, Anderson S et al. Twenty-five year follow-up of a randomized trial comparing radical mastectomy, total mastectomy, and total mastectomy followed by irradiation. N Engl J Med 2002; 347: 567-575

4 Veronesi U, Viale G, Paganelli G et al. Sentinel lymph node biopsy in breast cancer: ten-year results of a randomized controlled study. Ann Surg 2010; 251: 595-600

5 Bilimoria KY, Bentrem DJ, Hansen NM et al. Comparison of sentinel lymph node biopsy alone and completion axillary lymph node dissection for node-positive breast cancer. J Clin Oncol 2009; 27: 2946-2953

6 de Boer M, van Deurzen CH, van Dijck JA et al. Micrometastases or isolated tumor cells and the outcome of breast cancer. N Engl J Med 2009; 361: 653-663

7 Yi M, Giordano SH, Meric-Bernstam Fet al. Trends in and outcomes from sentinel lymph node biopsy (SLNB) alone vs. SLNB with axillary lymph node dissection for node-positive breast cancer patients: experience from the SEER database. Ann Surg Oncol 2010; 17 (Suppl. 3): 343-351

8 Clarke M, Collins R, Darby S et al. Effects of radiotherapy and of differences in the extent of surgery for early breast cancer on local recurrence and 15-year survival: an overview of the randomized trials. Lancet 2005; 366: 2087-2106

9 Cserni G, Bianchi S, Vezzosi V et al. The value of cytokeratin immunohistochemistry in the evaluation of axillary sentinel lymph nodes in patients with lobular breast carcinoma. J Clin Pathol 2006; 59: 518522

Deutschsprachige Zusatzinformationen mit deutschem Text online abrufbar unter: www.thieme-connect.de/ejournals/toc/gebfra. 